\title{
Critical Care before Lung Transplantation
}

\author{
Jin Gu Lee', Moo Suk Park², Su Jin Jeong ${ }^{3}$, Song Yee Kim², Sungwon Na ${ }^{4}$, Jeongmin Kim ${ }^{4}$, Hyo Chae Paik \\ ${ }^{1}$ Department of Thoracic and Cardiovascular Surgery, Divisions of ${ }^{2}$ Pulmonology and ${ }^{3}$ Infectious Disease, Department of Internal Medicine, and \\ ${ }^{4}$ Department of Anesthesiology, Yonsei University College of Medicine, Seoul, Korea
}

Lung transplantation is widely accepted as the only viable treatment option for patients with end-stage lung disease. However, the imbalance between the number of suitable donor lungs available and the number of possible candidates often results in intensive care unit (ICU) admission for the latter. In the ICU setting, critical care is essential to keep these patients alive and to successfully bridge to lung transplantation. Proper management in the ICU is also one of the key factors supporting long-term success following transplantation. Critical care includes the provision of respiratory support such as mechanical ventilation (MV) and extracorporeal life support (ECLS). Accordingly, a working knowledge of the common critical care issues related to these unique patients and the early recognition and management of problems that arise before and after transplantation in the ICU setting are crucial for long-term success. In this review, we discuss the management and selection of candidates for lung transplantation as well as existing respiratory support strategies that involve MV and ECLS in the ICU setting.

Key Words: critical care; donor selection; extracorporeal life support; lung transplantation; mechanical ventilation; preoperative care; transplant recipients

\section{INTRODUCTION}

Tremendous advances have been made since the modern era of lung transplantation (LTx) was launched in 1983, when the Toronto Lung Transplantation group performed the first successful LTx procedure [1]. The International Society for Heart and Lung Transplantation (ISHLT) registry contains data on 60,107 adult LTxs up to 2016. In 2015, a total of 4,122 adult LTx data were submitted from more than 140 programs [2]. LTx outcomes have steadily and reliably improved due to progress in surgical techniques, prophylaxis against infection, organ preservation, and immunosuppressive medications; as a result, the use of LTx has expanded. Currently, the actuarial median survival times are 7.4 and 4.6 years in double and single LTx cases, respectively [2].

However, the scarcity of suitable lung donors means that recipients must wait for extended periods, resulting in a high mortality rate among waitlisted patients [3-6]. The long waiting times and existing donor shortage often have forced physicians to place LTx candidates in the intensive care unit (ICU). Accordingly, it is increasingly important for intensivists to possess functional expertise regarding the critical care issues that they may encounter while treating patients on the waitlist for LTx. The early recognition and management of problems that arise

\section{Review Article}

Received: November 26, 2018

Accepted: November 27, 2018

Corresponding author

Hyo Chae Paik

Department of Thoracic and

Cardiovascular Surgery, Yonsei

University College of Medicine, 50

Yonsei-ro, Seodaemun-gu, Seoul

03722, Korea

Tel: +82-2-2228-2140

Fax: +82-2-393-6012

E-mail: HCPAIK@yuhs.ac

Copyright (@) 2018 The Korean Society of Critical Care Medicine

This is an Open Access article distributed under the terms of Creative Attributions Non-Commercial License (http:// creativecommons.org/li-censes/by-nc/4.0/ which permits unrestricted noncommercial use, distribution, and reproduction in any medium, provided the original work is properly cited. 
before and after LTx in the ICU setting are crucial for long-term success in lung recipients. The focus of this review will be the specific issues faced by LTx candidates in critical care settings. Disease indications for transplantation, preoperative ICU care, and extracorporeal life support (ECLS) as a bridge to LTx will be discussed. Donor management, which also needs to be overseen by the ICU team in order to identify potential organ donors and make appropriate referrals to a local procurement organization, will additionally be addressed [7-10].

\section{CRITICAL CARE FOR LTx CANDIDATES}

\section{Indications for LTx}

According to the ISHLT registry data, the major indications for LTx are chronic obstructive pulmonary disease/emphysema/ $\alpha$-1-antitrypsin deficiency (31.1\%), idiopathic interstitial pneumonia (IIP; 24.8\%), cystic fibrosis (CF; 15.6\%), interstitial lung disease-non-IIP (5.5\%), $\alpha$-1-antitrypsin deficiency (5.0\%), retransplantation (4.0\%), idiopathic primary pulmonary hypertension (IPAH) (2.9\%), non-CF bronchiectasis (2.7\%), sarcoidosis (2.5\%), pulmonary hypertension-non-IPAH (1.5\%), lymphangioleiomyomatosis and tuberous sclerosis (1.0\%), bronchiolitis obliterans $(0.9 \%)$, connective tissue disease $(0.8 \%)$, cancer $(0.1 \%)$, and other (1.8\%), respectively [2]. In Korea, idiopathic pulmonary fibrosis (IPF) was determined to be the most common disease entity and was involved in about $62 \%$ of all LTx recipient cases of the Korean Network for Organ Sharing registry in 2016 (Table 1) [11,12].

All circumstances that are unique to individual LTx candidates need to be considered by an intensivist. Patients with

Table 1. Disease entities necessitating lung transplantation from 2012 to 2016

\begin{tabular}{lrrrrr}
\hline Disease & 2012 & 2013 & 2014 & 2015 & 2016 \\
\hline Total & 37 & 46 & 55 & 64 & 89 \\
Asbestosis & & & 1 & & 1 \\
Bronchiectasis & 6 & 1 & 2 & 4 & 4 \\
Cystic fibrosis & 1 & & & & \\
Eisenmenger syndrome & & & & & 1 \\
Emphysema & & & & & 3 \\
Idiopathic pulmonary fibrosis & 12 & 22 & 25 & 30 & 44 \\
Lymphangioleiomyomatosis & 2 & 1 & 2 & & 1 \\
Primary pulmonary hypertension & 1 & 3 & & 2 & 3 \\
Bronchiolitis obliterans (after transfer) & 3 & 5 & 5 & 6 & 3 \\
Other & 12 & 14 & 20 & 22 & 29 \\
\hline Data from Kon
\end{tabular}

Data from Korean Network for Organ Sharing [11].

\section{KEY MESSAGES}

- The management and selection of candidate in ICU (intensive care unit) is crucial for the success of lung transplantation.

- The education of intensivists in the care of brain dead patients affects both procurement rates and leads to improved posttransplant outcomes.

- Extracorporeal life support (ECLS) could rescue a deteriorating patient on waitlist until suitable lungs become available.

IPF and some connective tissue disease-related interstitial lung diseases are often older. Many of these patients present with a combination of coronary diseases, diabetes, secondary pulmonary hypertension, and right-side heart dysfunction or failure $[13,14]$. Residual right heart dysfunction is also common in patients with IPAH after transplantation, and in such patients, it is necessary to pay particular attention to cardiac hemodynamics, as they frequently require increased right-side filling pressures to ensure hemodynamic stability.

\section{Respiratory Support for LTx Candidates}

Ventilator support in the ICU prior to LTx is associated with a $58 \%$ higher risk of mortality within 1 year post-LTx [15]. However, over the last decade, factors including technical advances, urgency-driven allocation systems, and reports of respiratory support yielding favorable outcomes have led to a steady increase in the proportion of LTx candidates receiving respiratory support by means of mechanical ventilation (MV) and/or ECLS. In the United States, only $3.7 \%$ of transplant recipients were admitted to the ICU pre-transplantation; this proportion increased dramatically to $14.1 \%$ in 2013 [16].

In patients with pulmonary disease who are considered to have a chance of recovering, endotracheal intubation with MV is considered to be an acceptable management measure. In the 1990s, a small retrospective single-center analysis and several case series showed heterogeneous results for MV as a way to bridge end-stage lung disease patients to LTx [17-19]. Previous studies reported a 1-year survival rate between $25 \%$ and $87 \%$ for the use of MV in such patients [20-24]. The LTx candidates who received MV in those studies were highly diverse, ranging from patients who were alert and even mobile while receiving long-term ventilation to patients who were intubated with high airway pressures and deeply sedated. Ventilator-induced damage is a particular concern in the latter group, as are ICU-related complications, such as airway colo- 
nization, nosocomial infections, vascular complications, pressure ulcers, delirium, and critical illness polyneuropathy/myopathy. These factors increase mortality both while patients are on the waitlist and post-LTx. Furthermore, the neurological status of LTx candidates on MV support may be uncertain (in particular after emergency intubation or cardiopulmonary resuscitation) and they may have been evaluated to a limited extent. For these reasons, some centers are hesitant to accept patients receiving MV as LTx candidates, although others accept carefully selected patients under MV, but reevaluate their transplant potential on a daily basis. A study of 100 ventilated candidates at a single center awaiting LTx conducted from 2004 to 2009 showed that transplantation was performed in $60 \%$ of cases, with a 1-year survival rate of $57 \%$ [25]. The "US experience," which is based on data gathered by the United Network for Organ Sharing (UNOS) from multiple centers between 1987 and 2008, analyzed 587 ventilated patients who proceeded to LTx and reported a 1-year survival rate of $62 \%$ [19].

Similar to MV, ECLS has become an accepted tool for bridging patients either to recovery or to transplantation. ECLS has recently been used with increasing frequency as a result of significant technical advances. In 2013, 4.8\% of the recipients in the United States were on ECLS at the time of transplant versus $0.6 \%$ in 2003. Major improvements in ECLS include the introduction of centrifugal pumps, dual-lumen cannulas, and miniaturized systems; the development of polymethylpentene oxygenator membranes; and the use of heparin-coated circuits, all of which have made patient transport easier [2628]. These developments may have led to the more widespread recent use of ECLS as a bridge to LTx [29-31].

The use of ECLS without MV (referred to as "awake ECLS") in patients with respiratory failure is also attracting attention, since it allows patients to receive ECLS while remaining nonintubated, nonsedated, and awake. The primary advantage of "awake ECLS" is that it enables the complications and disadvantages associated with sedation and MV to be avoided [3235]. The bridging role of ECLS will be discussed later.

\section{Risk of Candidates: Bridging to LTx}

The management of LTx candidates who become acutely ill while on the waitlist poses a challenge to critical care practitioners. Given the unpredictable nature of available donors, the ICU care of such patients is potentially prolonged. Timesensitive issues such as nutritional status, functional capacity, and infection avoidance become a focus of care in an effort to maintain listing eligibility.
The requirement of MV has been considered as a contraindication for active listing for LTx at most centers due to the fear of poor outcomes. UNOS data for LTx collected between 1987 and 2008 demonstrated these fears [19]. The authors showed that, of the 15,934 transplants performed, 586 patients were on MV and 51 were on ECLS at the time of transplantation, respectively, and both scenarios contributed to the highest lung allocation scores. Survival rates were significantly worse in both MV- and ECLS-supported patients; the 1-year survival rates were $72 \%$ for the 51 ECLS-bridged patients and $93 \%$ for the unsupported patients.

Recently, preoperative life support of potential recipients has evolved with active rehabilitation and advanced ECLS technology. The concept of "bridging to transplantation" can be performed, often with concurrent aggressive rehabilitation and physical therapy if at all possible [36,37]. Technical advances in the redesign of circulatory pumps, membrane oxygenators, and venous catheters have now made less invasive ECLS support feasible without immobilizing or paralyzing patients in most cases. Smaller bilumen catheters introduced into the jugular vein and the inferior and superior vena cava to drain venous blood and simultaneously provide oxygenated blood into the right atrium [38] may potentially allow patients to be awake, nonventilated, and ambulatory during ECLS support. As this field is rapidly evolving, further research is necessary regarding the selection of appropriate patients.

\section{Candidate Selection on Respiratory Support}

In the current consensus document of the ISHLT, recommendations are presented for the selection of candidates for LTx who are receiving respiratory support [27]. MV and ECLS are considered "relative" contraindications, leaving room for them to be used in carefully selected cases. For candidates on respiratory support, it is also important to consider absolute contraindications to LTx (e.g., recent or ongoing addictive drug abuse, grade III obesity, nonadherence, a recent history of malignancy, or irreversible dysfunction of another major organ system). However, other forms of organ dysfunction that can be corrected by ECLS (e.g., acute prerenal kidney injury or hypoxemic hepatitis) may not be regarded as contraindications.

A consensus is emerging that patients who have additional contraindications (e.g., being over 60 years of age and/or with prior poor muscle status) and require mechanical respiratory support generally show poor outcomes and should not be accepted as viable transplant candidates. This recommendation is based on a study of experiences from a single center report- 


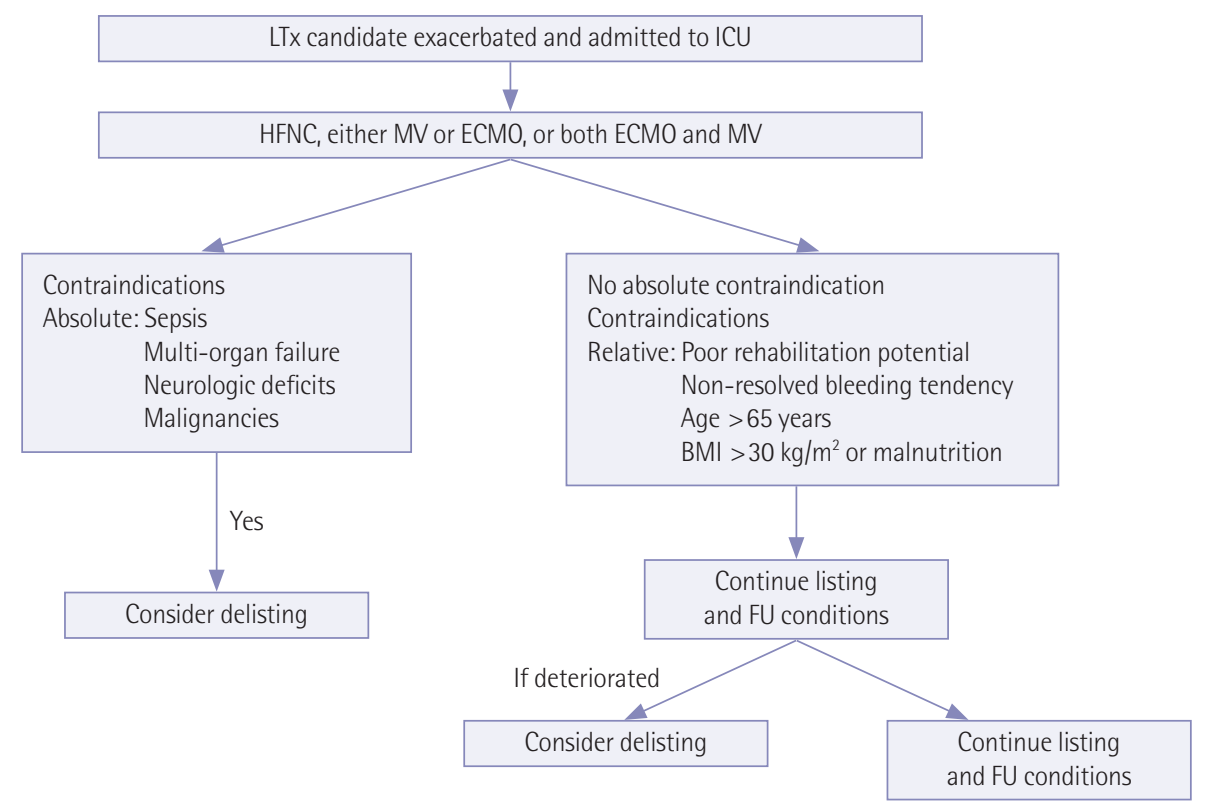

Figure 1. Practical algorithm for selection of candidates on respiratory support. LTx: lung transplantation; ICU: intensive care unit; HFNC: high-flow nasal cannula; MV: mechanical ventilation; ECMO: extracorporeal membrane oxygenation; BMI: body mass index; FU: follow-up.

ing that adult LTx patients on ECLS who were over 60 years of age showed significantly poorer survival than their younger counterparts [39]. Individuals experiencing acute respiratory failure (e.g., pneumonia or acute respiratory distress syndrome) are usually not considered to be suitable LTx candidates. The potential of recovery from the underlying disease, the scarcity of donors, and limitations in the ability to make an early prediction of survival in acute respiratory distress syndrome patients are the reasons for this critical appraisal.

A thorough evaluation of the recipient's transplant candidacy and recovery potential must be made before deciding to initiate mechanical respiratory support. In LTx candidates, ECLS support should only be performed by experienced specialists at dedicated transplant centers, and the transplant team should closely consult with the intensivists (Figure 1).

\section{Ethical Issues}

Ethical dilemmas are a major concern related to the noncritical use of ECLS in the ICU in patients without transplant or recovery potential, since it is a resource-intense technology $[40,41]$. In the absence of alternative treatments for respiratory failure, the assessment of all contraindications to transplantation and the patient's recovery potential are imperative before initiating mechanical respiratory support, in order to avert the "dead end" or "bridge to nowhere" scenario.

Furthermore, a further evaluation may rule out transplantation, even in patients who were initially considered to be suitable candidates. Most often, bridging failure in patients on ECLS and/or MV results from neurological complications, multiorgan failure, or uncontrolled sepsis. In futile cases, the transplant team usually makes a decision to withdraw life support, which is often preceded by a consultation with members of the patient's family. It may also be appropriate to discuss organ donation with the patient and/or family members.

In cases where an alert patient is on ECLS, with no further therapeutic options, withdrawing life support is particularly difficult, even though doing so follows established principles in end-of-life management in critical care medicine. Withdrawal of care from patients on ECLS is a challenging issue that should be approached on an individual basis, with due consideration of regional, legal, and/or ethical heterogeneity.

The process for withdrawal of care from patients on ECLS has not been standardized. Adequate pain control with sufficient sedation should be given before and during the withdrawal process. ECLS is often switched to room air, and oxygen gas flow is reduced. At this time, the patient's status on the waitlist should be switched to inactive.

\section{Donor Management in ICU}

The continued lack of supply of organs in contrast to the increasing demand for lungs has spurred interest in expanding the traditional definition of the "ideal" lung donor that has contributed to lung acceptance rates of less than $20 \%$. The current criteria for ideal lung donors are as follows: age $<55$ years, $\mathrm{PaO}_{2}$ 
$>300$, minimal smoking history, and clear chest X-rays [42]. Aggressive donor management by the team caring for a potential donor lung may result in improvement of the function of "extended" donor lungs closer to the range of the "ideal" organ, thus increasing lung donor conversion rates [43-45]. A protocol-based approach for the management of potential organ donors, particularly ventilatory management, is an effective way to standardize variation in practice styles in the community and to improve donor conversion rates [46]. The education of intensivists in the care of brain-dead patients is important, as proper management of such patients may affect both procurement rates and lead to improved immediate posttransplant outcomes. Naik and Angel [47] reported that brain death elicits hemodynamic instability, the activation of inflammatory pathways, and endocrine dysfunction, which can profoundly impact the quality and function of donated lungs. In conjunction with an active local donor procurement organization, active donor management is necessary to treat these homeostatic derangements. Mascia et al. [48] showed in a survey of 15 ICUs in Italy that a clear tendency exists toward maintaining potentially injurious ventilatory management strategies and not performing recruitment maneuvers after the pronouncement of brain death. This same group also recently demonstrated the beneficial effects of employing lung protective ventilatory strategies (tidal volume, $6-8 \mathrm{mg} / \mathrm{kg}$ predicted body weight; positive endexpiratory pressure [PEEP], 8-10 $\mathrm{cmH}_{2} \mathrm{O}$ ) on potential lung donors in a randomized controlled trial as compared with conventional ventilatory parameters (tidal volume, $10-12 \mathrm{mg} / \mathrm{kg}$ predicted body weight; PEEP, 3-5 $\mathrm{cmH}_{2} \mathrm{O}$ ) [49]. Of the 118 patients enrolled in the study, $54 \%$ of the donors from the lung protective ventilator strategy group went on to donate lungs versus $27 \%$ of the conventional ventilatory strategy group. The outcomes of lung recipients from both groups were not different after 6 months [49]. The aforementioned reports indicate the importance of donor management.

\section{ECLS BRIDGING TO LTx}

Many candidates for LTx die on the waitlist because they are too sick to survive until lungs are available. The mortality rate for waitlist patients remains as high as 50\% [25]. Maximal MV is applied in these patients, and refractory hypercapnia and/ or hypoxia commonly develops despite ventilator support. ECLS can rescue the patient until suitable lungs become available as a bridging strategy. Although initial attempts to use ECLS as a bridge to LTx failed to show good outcomes, recent advancements in ECLS equipment, such as heparin-coated circuits, centrifugal pump, and polymethylpentene oxygenators, have made it possible to more successfully bridge to LTx.

\section{Indications}

Patients who are generally candidates for LTx may also be candidates for ECLS bridging to LTx. In particular, if a patient already on the waiting list for LTx experiences a rapid deterioration, then ECLS bridging to LTx is considered. However, given the scarcity of donor lungs, consideration should be paid to the possibility of recovery, and patients should be carefully selected. In general, patients who are young and have good prospects for rehabilitation, as well as those without other or-
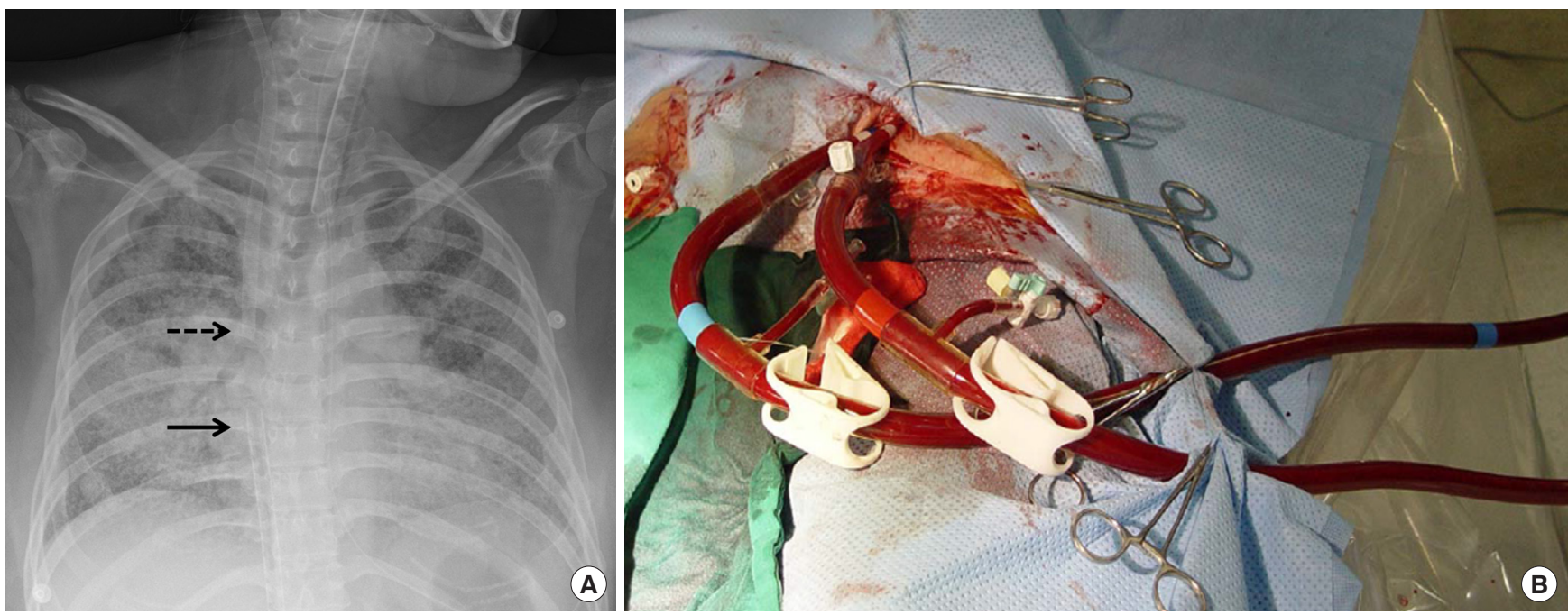

Figure 2. (A) Venovenous extracorporeal membrane oxygenation (ECMO), femoral vein for drainage (black arrow) and internal jugular vein for inflow (dotted arrow). (B) Venoarterial ECMO, femoral vein for drainage and femoral artery for inflow. 
gan dysfunction, are good candidates for ECLS [50]. Contraindications may vary from program to program and include the following: ineligibility to standard criteria, irreversible other organ dysfunction, sepsis and bacteremia, contraindications to systemic anticoagulation, and acute intracerebral hemorrhage or stroke. Relative contraindications include an age greater than 65 years, limitations in vascular access, obesity (body mass index $>30 \mathrm{~kg} / \mathrm{mg}^{2}$ ), frailty, and prolonged ventilator support (i.e., more than 7 days) [51]. If possible, the need for ECLS should be anticipated so that it is incorporated electively rather than emergently. Furthermore, patients who tolerate nonintubated and ambulatory ECLS may achieve better physical condition at the time of transplantation and can be good candidates for ECLS bridging [52].

\section{ECLS Management}

Both venovenous (VV) and venoarterial (VA) modes are used in ECLS bridging. The configuration can be individualized and tailored for specific patients according to ventilator and hemodynamic requirements. If patients deteriorate and cannot oxygenate despite the use of ventilator support, but are hemodynamically stable, VV ECLS is favored. Generally, a femoral vein is used for drainage and an internal jugular vein is employed for inflow (Figure 2A). The advantages of VV mode in comparison with VA mode are fewer tendencies of bleeding, arterial thrombosis, and neurologic complications. However, if there is significant resistance to pulmonary arterial flow, it can be less successful. VA ECLS support is required in patients with cardiac dysfunction or elevated pulmonary vascular resistance, and it can be used in several configurations. Oxygenated blood is delivered to the body through an artery, which bypasses the pulmonary circulation, and deoxygenated blood is drained from the body using a vein. For patients who have severe primary or secondary pulmonary hypertension, pumpless pulmonary artery to left atrium bypass or atrial septostomy can be another option. Femoral VA ECLS (Figure 2B) is a common arrangement, but upper-body oxygenation is compromised in this case when the patient's cardiac function is intact. Central VA is another option for patients who show a compromise of both lung and cardiac function. Central VA is achieved through a median sternotomy with excellent oxygenation and no risk of limb ischemia, but the disadvantage of this method is its invasiveness.

\section{Outcomes}

The outcomes of bridging ECLS to LTx have improved over the last decade. Between 2000 and 2002, the 1-year survival rate in the United States was 25\% [53], which increased up to $74 \%$ by 2009 to 2011 . This increase in survival is attributed to advancements in circuit technique, patient management, and patient selection [54]. Procedure results depend on several factors including disease entity, patient age, transplant volume, ventilator mode, and time on ECLS. An age of greater than 35 years was an independent risk factor in patients who were bridged [53]. However, patients older than 65 years with no risk factors can be generally considered for ECLS bridging. A low-volume center (i.e., one that performs 1 to 5 transplants/ year) showed an adjusted hazard ratio for mortality of 2.74 as compared with a high-volume center (i.e., one that performs more than 15 transplants/year) [55]. Patients with less than 14 days of ECLS showed a 1-year survival rate of $100 \%$, and those who were on ECLS for more than 14 days prior to transplantation had a 1-year survival rate of $50 \%$. Separately, patients who required noninvasive ventilation on the waitlist had a mortality rate of $20 \%$ and a 1 -year survival rate of $60 \%$ after transplantation, whereas patients on intubation had a mortality rate of

Table 2. Factors affecting posttransplant survival in patients on ECMO support

\begin{tabular}{lll}
\hline Factor & \multicolumn{1}{c}{ Favorable } & Unfavorable \\
\hline Age $(y r)$ & $<50$ & $>60$ \\
Total bilirubin & Normal-mild elevation & $>3$ \\
Pulmonary hypertension & Normal-mild & Severe \\
ECM0 duration (day) & $<14$ & $>14$ \\
Rehabilitation potential & Awakening and physical therapy & Prolonged immobility \\
SOFA score & $<6$ & $>9$ \\
Ventilation & Noninvasive & Prolonged mechanical ventilation \\
Complication & No & Major bleeding, infection, end-organ complications on ECM0 \\
Retransplantation & No & Retransplantation interval of less than 1 year \\
\hline
\end{tabular}

ECMO: extracorporeal membrane oxygenation; SOFA: Sequential Organ Failure Assessment. 
$40 \%$ and a 1-year survival rate of $47 \%$ [56]. Factors to be considered in ECLS bridging to LTx are summarized in Table 2.

\section{Complications}

Several complications can occur when applying ECLS in transplant candidates. Bleeding is a major complication because of heparin use to maintain an activated clotting time of 160 and 200 seconds. Cannula site problems and limb ischemia are also common. Neurologic examinations should be performed regularly. Furthermore, the immobility of patients with ECLS leads to physical deconditioning and myopathy. To maintain patient condition, physical therapy is mandatory, and the use of paralytic agents and steroids should be kept to a minimum.

\section{CONCLUSIONS}

Critical care of LTx candidates is crucial for both successful bridging to LTx and long-term success of lung recipients after transplant. Outcomes of candidates for LTx in the ICU are poor. Candidates may go on to undergo a successful transplantation or die according to the care they receive in the ICU. From the selection process, attention should focus on the potential of rehabilitation and recovery after transplantation. Furthermore, mechanical respiratory support is a key to maintaining patient oxygenation and organ perfusion until suitable donor lungs are available. Both MV and ECLS are vital for end-stage lung diseases. The configuration of ECLS should be tailored according to patient hemodynamic requirements, and possible complications should be expected. For this purpose, a multidisciplinary approach is needed.

\section{CONFLICT OF INTEREST}

No potential conflict of interest relevant to this article was reported.

\section{ORCID}

Jin Gu Lee https://orcid.org/0000-0003-2767-6505

Moo Suk Park https://orcid.org/0000-0003-0820-7615

Su Jin Jeong https://orcid.org/0000-0003-4025-4542

Song Yee Kim https://orcid.org/0000-0001-8627-486X Sungwon $\mathrm{Na}$ https://orcid.org/0000-0002-1170-8042

Jeongmin Kim https://orcid.org/0000-0002-0468-8012

Hyo Chae Paik https://orcid.org/0000-0001-9309-8235

\section{REFERENCES}

1. Toronto Lung Transplant Group. Unilateral lung transplantation for pulmonary fibrosis. N Engl J Med 1986;314:1140-5.

2. Chambers DC, Yusen RD, Cherikh WS, Goldfarb SB, Kucheryavaya AY, Khusch $\mathrm{K}$, et al. The registry of the International Society for Heart and Lung Transplantation: thirty-fourth adult lung and heart-lung transplantation report-2017; focus theme: allograft ischemic time. J Heart Lung Transplant 2017;36:104759.

3. Egan TM, Bennett LE, Garrity ER, Grover FL, Ring WS, Robbins RC, et al. Predictors of death on the UNOS lung transplant waiting list: results of a multivariate analysis. J Heart Lung Transplant 2001;20:242.

4. De Meester J, Smits JM, Persijn GG, Haverich A. Listing for lung transplantation: life expectancy and transplant effect, stratified by type of end-stage lung disease, the Eurotransplant experience. J Heart Lung Transplant 2001;20:518-24.

5. Hosenpud JD, Bennett LE, Keck BM, Edwards EB, Novick RJ. Effect of diagnosis on survival benefit of lung transplantation for end-stage lung disease. Lancet 1998;351:24-7.

6. Charman SC, Sharples LD, McNeil KD, Wallwork J. Assessment of survival benefit after lung transplantation by patient diagnosis. J Heart Lung Transplant 2002;21:226-32.

7. Carlin BW, Lega M, Veynovich B. Management of the patient undergoing lung transplantation: an intensive care perspective. Crit Care Nurs Q 2009;32:49-57.

8. Lau CL, Patterson GA, Palmer SM. Critical care aspects of lung transplantation. J Intensive Care Med 2004;19:83-104.

9. Pierre AF, Keshavjee S. Lung transplantation: donor and recipient critical care aspects. Curr Opin Crit Care 2005;11:33944.

10. Simpson KP, Garrity ER. Perioperative management in lung transplantation. Clin Chest Med 1997;18:277-84

11. Korean Network for Organ Sharing. KONOS data registry report 2016 [Internet]. Seoul: Korean Network for Organ Sharing; 2017 [cited 2018 Nov 25]. Available from: https://www. konos.go.kr/konosis/index.jsp.

12. Paik HC. Current perspective of lung transplantation. J Korean Med Assoc 2016;59:119-24.

13. Kim CY, Park JE, Leem AY, Song JH, Kim SY, Chung KS, et al. Prognostic value of pre-transplant mean pulmonary arterial pressure in lung transplant recipients: a single-institution experience. J Thorac Dis 2018;10:1578-87.

14. Park JE, Kim SY, Song JH, Kim YS, Chang J, Lee JG, et al. Comparison of short-term outcomes for connective tissue diseaserelated interstitial lung disease and idiopathic pulmonary fi- 
brosis after lung transplantation. J Thorac Dis 2018;10:153847.

15. Yusen RD, Edwards LB, Kucheryavaya AY, Benden C, Dipchand AI, Dobbels F, et al. The registry of the International Society for Heart and Lung Transplantation: thirty-first adult lung and heart-lung transplant report-2014; focus theme: retransplantation. J Heart Lung Transplant 2014;33:1009-24.

16. Valapour M, Skeans MA, Heubner BM, Smith JM, Hertz MI, Edwards LB, et al. OPTN/SRTR 2013 Annual data report: lung. Am J Transplant 2015;15 Suppl 2:1-28.

17. Peek GJ, Mugford M, Tiruvoipati R, Wilson A, Allen E, Thalanany MM, et al. Efficacy and economic assessment of conventional ventilatory support versus extracorporeal membrane oxygenation for severe adult respiratory failure (CESAR): a multicentre randomised controlled trial. Lancet 2009;374:135163.

18. Elizur A, Sweet SC, Huddleston CB, Gandhi SK, Boslaugh SE, Kuklinski CA, et al. Pre-transplant mechanical ventilation increases short-term morbidity and mortality in pediatric patients with cystic fibrosis. J Heart Lung Transplant 2007;26: 127-31.

19. Mason DP, Thuita L, Nowicki ER, Murthy SC, Pettersson GB, Blackstone EH. Should lung transplantation be performed for patients on mechanical respiratory support? The US experience. J Thorac Cardiovasc Surg 2010;139:765-73.el.

20. Orens JB, Estenne M, Arcasoy S, Conte JV, Corris P, Egan JJ, et al. International guidelines for the selection of lung transplant candidates: 2006 update: a consensus report from the Pulmonary Scientific Council of the International Society for Heart and Lung Transplantation. J Heart Lung Transplant 2006;25: 745-55.

21. Bartz RR, Love RB, Leverson GE, Will LR, Welter DL, Meyer KC. Pre-transplant mechanical ventilation and outcome in patients with cystic fibrosis. J Heart Lung Transplant 2003;22: 433-8.

22. Baz MA, Palmer SM, Staples ED, Greer DG, Tapson VF, Davis DD. Lung transplantation after long-term mechanical ventilation: results and 1-year follow-up. Chest 2001;119:224-7.

23. Christie JD, Edwards LB, Aurora P, Dobbels F, Kirk R, Rahmel AO, et al. The registry of the International Society for Heart and Lung Transplantation: twenty-sixth official adult lung and heart-lung transplantation report-2009. J Heart Lung Transplant 2009;28:1031-49.

24. Meyers BF, Lynch JP, Battafarano RJ, Guthrie TJ, Trulock EP, Cooper JD, et al. Lung transplantation is warranted for stable, ventilator-dependent recipients. Ann Thorac Surg 2000;70: 1675-8.
25. Gottlieb J, Warnecke G, Hadem J, Dierich M, Wiesner O, Fühner $\mathrm{T}$, et al. Outcome of critically ill lung transplant candidates on invasive respiratory support. Intensive Care Med 2012;38: 968-75.

26. Qiu F, Lu CK, Palanzo D, Baer LD, Myers JL, Undar A. Hemodynamic evaluation of the Avalon Elite bi-caval dual lumen cannulae. Artif Organs 2011;35:1048-51.

27. Weill D, Benden C, Corris PA, Dark JH, Davis RD, Keshavjee S, et al. A consensus document for the selection of lung transplant candidates: 2014--an update from the Pulmonary Transplantation Council of the International Society for Heart and Lung Transplantation. J Heart Lung Transplant 2015;34:1-15.

28. Jackson A, Cropper J, Pye R, Junius F, Malouf M, Glanville A. Use of extracorporeal membrane oxygenation as a bridge to primary lung transplant: 3 consecutive, successful cases and a review of the literature. J Heart Lung Transplant 2008;27: 348-52.

29. Gulack BC, Hirji SA, Hartwig MG. Bridge to lung transplantation and rescue post-transplant: the expanding role of extracorporeal membrane oxygenation. J Thorac Dis 2014;6:1070-9.

30. Lehr CJ, Zaas DW, Cheifetz IM, Turner DA. Ambulatory extracorporeal membrane oxygenation as a bridge to lung transplantation: walking while waiting. Chest 2015;147:1213-8.

31. Hoopes CW, Kukreja J, Golden J, Davenport DL, Diaz-Guzman E, Zwischenberger JB. Extracorporeal membrane oxygenation as a bridge to pulmonary transplantation. J Thorac Cardiovasc Surg 2013;145:862-7.

32. Fuehner T, Kuehn C, Hadem J, Wiesner O, Gottlieb J, Tudorache I, et al. Extracorporeal membrane oxygenation in awake patients as bridge to lung transplantation. Am J Respir Crit Care Med 2012;185:763-8.

33. Chastre J, Fagon JY. Ventilator-associated pneumonia. Am J Respir Crit Care Med 2002;165:867-903.

34. Hermans G, De Jonghe B, Bruyninckx F, Van den Berghe G. Clinical review: critical illness polyneuropathy and myopathy. Crit Care 2008;12:238.

35. Vassilakopoulos T, Petrof BJ. Ventilator-induced diaphragmatic dysfunction. Am J Respir Crit Care Med 2004;169:336-41.

36. Strueber M. Bridges to lung transplantation. Curr Opin Organ Transplant 2011;16:458-61.

37. Turner DA, Cheifetz IM, Rehder KJ, Williford WL, Bonadonna D, Banuelos SJ, et al. Active rehabilitation and physical therapy during extracorporeal membrane oxygenation while awaiting lung transplantation: a practical approach. Crit Care Med 2011;39:2593-8

38. Javidfar J, Brodie D, Wang D, Ibrahimiye AN, Yang J, Zwischenberger JB, et al. Use of bicaval dual-lumen catheter for adult 
venovenous extracorporeal membrane oxygenation. Ann Thorac Surg 2011;91:1763-8.

39. Hayes D Jr, Whitson BA, Black SM, Preston TJ, Papadimos TJ, Tobias JD. Influence of age on survival in adult patients on extracorporeal membrane oxygenation before lung transplantation. J Heart Lung Transplant 2015;34:832-8.

40. Abrams DC, Prager K, Blinderman CD, Burkart KM, Brodie D. Ethical dilemmas encountered with the use of extracorporeal membrane oxygenation in adults. Chest 2014;145:876-82.

41. Paden ML, Conrad SA, Rycus PT, Thiagarajan RR; ELSO Registry. Extracorporeal life support organization registry report 2012. ASAIO J 2013;59:202-10.

42. Orens JB, Boehler A, de Perrot M, Estenne M, Glanville AR, Keshavjee S, et al. A review of lung transplant donor acceptability criteria. J Heart Lung Transplant 2003;22:1183-200.

43. Snell GI, Griffiths A, Levvey BJ, Oto T. Availability of lungs for transplantation: exploring the real potential of the donor pool. J Heart Lung Transplant 2008;27:662-7.

44. Van Raemdonck D, Neyrinck A, Verleden GM, Dupont L, Coosemans W, Decaluwé H, et al. Lung donor selection and management. Proc Am Thorac Soc 2009;6:28-38.

45. Snell GI, Westall GP. Donor selection and management. Curr Opin Organ Transplant 2009;14:471-6.

46. Angel LF, Levine DJ, Restrepo MI, Johnson S, Sako E, Carpenter A, et al. Impact of a lung transplantation donor-management protocol on lung donation and recipient outcomes. Am J Respir Crit Care Med 2006;174:710-6.

47. Naik PM, Angel LF. Special issues in the management and selection of the donor for lung transplantation. Semin Immunopathol 2011;33:201-10.

48. Mascia L, Bosma K, Pasero D, Galli T, Cortese G, Donadio P, et al. Ventilatory and hemodynamic management of potential organ donors: an observational survey. Crit Care Med 2006; 34:321-7.

49. Mascia L, Pasero D, Slutsky AS, Arguis MJ, Berardino M, Grasso $S$, et al. Effect of a lung protective strategy for organ donors on eligibility and availability of lungs for transplantation: a randomized controlled trial. JAMA 2010;304:2620-7.

50. Rajagopal K, Hoeper MM. State of the art: bridging to lung transplantation using artificial organ support technologies. J Heart Lung Transplant 2016;35:1385-98.

51. Collaud S, Benden C, Ganter C, Hillinger S, Opitz I, Schneiter D, et al. Extracorporeal life support as bridge to lung retransplantation: a multicenter pooled data analysis. Ann Thorac Surg 2016;102:1680-6.

52. Biscotti M, Sonett J, Bacchetta M. ECMO as bridge to lung transplant. Thorac Surg Clin 2015;25:17-25.

53. Hayanga AJ, Aboagye J, Esper S, Shigemura N, Bermudez CA, D'Cunha J, et al. Extracorporeal membrane oxygenation as a bridge to lung transplantation in the United States: an evolving strategy in the management of rapidly advancing pulmonary disease. J Thorac Cardiovasc Surg 2015;149:291-6.

54. Combes A, Bacchetta M, Brodie D, Müller T, Pellegrino V. Extracorporeal membrane oxygenation for respiratory failure in adults. Curr Opin Crit Care 2012;18:99-104.

55. Hayanga JW, Lira A, Aboagye JK, Hayanga HK, D'Cunha J. Extracorporeal membrane oxygenation as a bridge to lung transplantation: what lessons might we learn from volume and expertise? Interact Cardiovasc Thorac Surg 2016;22:406-10.

56. Crotti S, Iotti GA, Lissoni A, Belliato M, Zanierato M, Chierichetti $\mathrm{M}$, et al. Organ allocation waiting time during extracorporeal bridge to lung transplant affects outcomes. Chest 2013; 144:1018-25. 